\title{
"We sold the buffalo to pay for a brain scan" - a qualitative study of rural experiences with private mental healthcare providers in Uttar Pradesh, India
}

\begin{abstract}
The majority of persons with mental distress (PWMD) in India do not have access to care, and even those who seek care are pushed to attend private providers, given the weak and largely absent public mental health services framework. The aim of this study was to examine the experiences in help-seeking and with unethical health service provision among persons with mental distress in the Saharanpur and Bijnor districts of Uttar Pradesh. In-depth interviews were conducted with twenty persons with mental distress and their caregivers. Thematic analysis yielded four key findings about help-seeking: first, that it was syncretic and persistent; second, that expenditure for private care was high and often catastrophic; third, that investigations and care provided were pharmacological and predominantly irrational and excessive; and lastly, that help-seeking was abandoned. This study demonstrates that PWMD are particularly vulnerable to exploitation by private providers with illnesses that are stigmatising, poorly understood, chronic, relapsing, and disabling and that often require complex management. Responding to mental distress requires multiple empowering and interacting policy and programme initiatives that must include regulation of private and public providers, resources, and actions to strengthen public and primary mental healthcare and promotion of mental health competence in communities.
\end{abstract}

\section{Introduction}

Mental disorders contribute $11.8 \%$ of the total burden of disease in India (1), yet only one out of ten persons with mental distress (PWMD) accesses allopathic mental health services (2) Poor access to care is exacerbated by the low numbers of every cadre of mental health professional, particularly in rural areas (2).

At a public health system level, the low priority given to the health needs of PWMD is evident in a national health budget

\footnotetext{
Authors: Kaaren Mathias (corresponding author - kaaren@eha-health org), Programme Manager, Mental Health, Emmanuel Hospital Association, Landour Community Hospital, Mussoorie 248 179, INDIA; KS Jacob (ksjacob1959@gmail.com). Professor of Psychiatry (Retd), Christian Medical College, Ida Scudder Road, Vellore 632 004, INDIA; Abhay Shukla (abhayshukla1@gmail.com), Senior Programme Coordinator, SATHI, Dahanukar Colony, Kothrud, Pune 411 029, INDIA.

To cite: Mathias K, Jacob KS, Shukla A. "We sold the buffalo to pay for a brain scan" - a qualitative study of rural experiences with private mental healthcare providers in Uttar Pradesh, India. Indian J Med Ethics. 2019 OctDec;4(4) NS:282-7.DOI: 10.20529/IJME.2019.057.

Published online on September 17, 2019.

Manuscript Editor: Mala Ramanathan

Peer Reviewers: Sunu Thomas and an anonymous reviewer

CIndian Journal of Medical Ethics 2019
}

that in 2016 allocated less than 2\% to mental health (3). India's National Mental Health Programme (NMHP) was launched in 1982, but is widely recognised as poorly implemented, ineffective, and grossly under-resourced $(4,5)$. In 2013, at the time of our study, there were just ten government psychiatrists employed by the Department of Health of the state of Uttar Pradesh, equating to one government psychiatrist per twenty million people.

Private mental health services are also troubled. The malaise of the private sector in India has been well described and includes irrational care, excessive investigation, kickbacks to doctors for ordering diagnostic tests, inappropriate and excessive prescription, over-pricing, and very limited regulation of health services (6-8). About 39 million people in India are pushed into poverty by catastrophic out-ofpocket health expenditure per annum (9). The impacts of the private sector are perhaps doubly negative when considering mental healthcare provision. Illness of the mind is even more mysterious and unknowable to most patients than physical illness, making them particularly vulnerable to over-investigation. Inappropriate brain imaging-computer tomography (CT) or magnetic resonance imaging (MRI)—scans benefit avaricious private practitioners via the ubiquitous system of kickbacks to doctors for ordering imaging $(10,11)$ but hugely harm poorer patients and their families.

The chronic nature of mental illness and its tendency to relapse also present a fertile field for polypharmacy over extended periods, and studies show this is a prevalent practice among psychiatrists in India $(10,12)$. One study of prescribing patterns for psychotropic medication in a tertiary-care hospital in Eastern India showed that $76.6 \%$ of the patients had suffered from polypharmacy as evaluated by a consultant psychiatrist (13).

While several authors have discussed the negative impacts of unregulated private health service provision in India (1012), almost none have examined the vulnerability of PWMD to private health services that are often predatory. The aim of this study was to describe the experiences of persons with mental distress in help seeking and unethical practices of mental health service provision in western Uttar Pradesh. Since they are particularly effective at providing an emergent and in-depth understanding of an issue (14), qualitative methods were adopted for this study.

This paper was part of a larger study that examined experiences of help seeking, exclusion and inclusion, and caregiving among persons with severe mental distress in Uttar Pradesh $(15,16)^{*}$. 


\section{Methods}

\section{Setting}

Set in the vibrant bustling green sugar cane fields and densely populated brick villages of Bijnor and Saharanpur districts in western Uttar Pradesh, this research was hosted by two community health and development teams of the Emmanuel Hospital Association (EHA). EHA is a 45-year-old non-profit organisation with a network of 20 rural hospitals and 42 community health and development projects across northern India. In both districts, the NMHP had not been implemented, there were no government mental health services within three hours of travel, and primary care services did not provide treatment or psychiatric medicines.

\section{Sample selection}

During May 2013, potential participants were identified by EHA community-based team members working in the community and screened by the principal researcher using the Global Mental Health Assessment Tool (17). The first 20 persons identified with PWMD who fulfilled the criterion of having disabling mental distress (being unable to fulfil or participate in household or income generation responsibilities) and consented to participate were included. The majority had no current access to mental healthcare (they were not regularly attending any type of care provider or taking any medications) but this was not a criterion for inclusion. As seven of the PWMD were not well enough to meaningfully participate in an interview (as assessed through mini-mental state examination by medical doctor, $\mathrm{KM}$ ), their primary caregivers (as identified by all household members including the affected person) were interviewed as a proxy form of participation to capture the experiences of the persons most profoundly unwell. All participants gave informed consent to participate, and caregivers also gave personal consent and consent for participation of their family members.

\section{Data collection}

A research assistant from Uttarakhand, who had worked for many years in western Uttar Pradesh, conducted indepth interviews $(n=40)$ with participants $(n=20)$ and their caregivers $(n=20)$ in participants' homes in May and June 2013, using a semi-structured guide that probed for experiences of help seeking, access to care, and other aspects related to social exclusion and inclusion that have been reported elsewhere $(15,16)^{*}$. Additionally, the lead researcher reviewed patient-held records of consultations with private and government providers during home-based interviews, including reports of radiological investigations for mental illness, prescriptions, and the diagnoses and assessments by health providers. Key findings of this document review were noted in a research diary.

\section{Data analysis}

The data was analysed inductively and thematically using an approach inspired by Braun and Clarke (14). Thematic analysis offers an accessible and theoretically flexible approach to analysing qualitative data (14) which was well suited to the aims of this paper seeking an in-depth understanding of a little-explored topic. The lead researcher (a public health physician employed by the EHA as the mental health programme manager was a citizen of New Zealand, born and residing in India for many years) inductively coded seven representative transcripts, yielding over 50 codes as a preliminary coding framework. The remaining 33 transcripts were then coded using this framework, with ongoing inductive codes emerging, and these were then thematically analysed. Four themes related to help seeking and private care emerged by recognition of consistent patterns inherent in the data.

\section{Ethics}

All participants gave written consent to participate in the study. Ethics approval was obtained from the Emmanuel Hospital Association Institutional Ethics Committee as Protocol 95 in New Delhi on April 25, 2013.

\section{Findings}

The four key themes are presented here to reflect the temporal sequence of help seeking:

\section{Help seeking is syncretic and persistent}

PWMD and their caregivers sought help from many different providers, traditional and biomedical, public and private, formal and informal, and religious and secular.

Help seeking encounters also informed explanatory frameworks. Several participants adopted and repeated back the pseudoscientific explanations given by private healthcare providers, purportedly representing Western biomedicine, such as "mental imbalance" and "thickening of the nuss (nerves)". An example is provided below:

"People say and we also say that someone has done something (like cursing) against our family. As well as my husband's illness, my brother had an injury and another brother has become an alcoholic. We also felt there might be something in the house... Later we took him for CT scan and we found he had thickened nerves. So we took him to the mental hospital and also to the maulvi (traditional Islamic healer)."

35-year old wife of PWMD

Efforts to obtain care were persistent and involved significant financial and time commitments by family members. If treatment by one provider proved ineffective, family members sought another provider. Part of help seeking was also trying to make sense of the symptoms and experiences, but often providers did not address these concerns.

One woman told us how she had travelled with her son to the dargah (shrine) at Balaji, Rajasthan (several days' journey by train from the study area). Others described seeking care in multiple cities, each place involving up to two days of travel. 


\section{Investigations and care were inadequate, exclusively pharmacological, and irrational}

Caregivers and PWMD reported that after travelling four or more hours to the nearest government-provided mental health service, they found it inadequate. Patients described consultations at the nearest government psychiatric hospital that typically lasted a maximum of ten minutes for a first consultation, and typically only two or three minutes in duration for repeat visits. Treatment only involved medication. Consultation records of all participants were examined by the lead researcher and revealed private services to be characterised by irrational investigations, polypharmacy, and unethical care. None of the interviewees described receiving or being offered counselling, psycho-social support, or talk therapy. Patient-held records and accounts suggested private practitioners frequently ordered investigations not typically required for psychotic illness (such as head X-rays and abdominal ultrasounds). One person reported that the doctor required her to have serial brain imaging investigations (CT scans) each month for three months. The following quote is that of a man describing a consultation with a private psychiatrist for his wife's symptoms, which were typical of a post-partum psychosis, a condition typically diagnosed clinically:

"After the birth of my son, my wife was speaking unnecessary and senseless things. We took her to a doctor who deals with patients who have a deficiency or imbalance of the brain. First, we took her to Moradabad, to Dr XX's clinic. A CT scan was done, which the doctor told us showed mental imbalance in the report, and he gave us medicines for 15 days."

30-year-old man, husband of a PWMD

Participants described treatment as almost exclusively pharmacological and some people also described receiving electro-convulsive therapy. Prescriptions included many preparations, often for 10 different medicines, each paid for out of pocket by patients. Patient-held records also showed prescription of many tonics and non-specific preparations, which are not accepted in evidence-based management guidelines. Rural medical practitioners (who, in this part of the country, do not have any formal medical training) prescribed psychotropic medication as well as unproven remedies such as intravenous infusion of Vitamin B12 to "treat" psychiatric presentations. A woman who described symptoms typical of a post-partum psychosis narrates how she was given a daily intravenous infusion in a nursing home in the following quote:

"The medicines cost Rs1000 per day, and additionally, I had to be taken to the doctor. It was very difficult for my husband, as he is a daily wage worker and the expenses were very high. Each day I was given a drip and returned home late in the evening. My children used to stay hungry all day."

35-year-old woman, PWMD

\section{Expenditure for private care high and often catastrophic}

Families affected described numerous experiences of healthcare service provision coming with a very high price tag. One family described how the costs of medicines were around Rs 500 per day (three times more than the family's daily income) so they bought the medicines for two weeks and then stopped medication to avoid debt. The economic impact of help seeking at times seriously compromised household wellbeing with loss of income in help-seeking which required both the PWMD and the primary caregiver to travel away from home. Many participants mentioned that the cost of diagnostic tests and treatment was so high that they had taken loans and accrued debt. One man even sold the family buffalo to pay for a brain scan for his wife, and another family had to sell land to cover the costs of a CT scan, as quoted here:

"A CT scan was done, and the report showed mental imbalance. He gave us medicines for 15 days. It was a big strain on our family, and to pay all the costs, I sold some land and also took up work as a daily-wage labourer in others' fields. We are still in debt, and all those loans are being paid slowly."

30-year-old man, husband of a PWMD

Costs were sometimes so high that participants reported going hungry. The daily realities of food, farming, and the environment they live in are entwined with mental health or ill-health. In the following quote, a husband describes how his family ran short of food and clothing as they sought to manage care for his wife when she was unwell with a post-partum psychosis:

"Things were difficult when she was getting treatment. When we used to visit the doctor, we used to struggle to manage food and even borrowed clothes. I took a loan and we were in debt, but no-one asked how we were managing. Borrowing clothes and money was the only option we had."

46-year-old man, husband of a PWMD

\section{Loss of hope and giving up on help seeking}

Affected families reported that after many years of help seeking, high expenses, and little positive outcome, they felt little hope for cure or care. Most participants had given up seeking care and were trying to manage as best they could. Caregivers and participants conveyed that health providers were unable to comprehend their worlds with the tangled mix of distressing symptoms and socioeconomic difficulties in a way that provided relief or care. Here is an account by a 28-year-old woman that provides her own critical analysis and summarises the experiences of irrational care, persistent help seeking, and weariness at the ways in which vulnerable people are exploited:

"First, my head X-ray was done by doctors in Seohara. They said there is inflammation in the nerves. They gave me an IV drip, but after some time, the problem started again. Then $\mathrm{Dr}$ $X X$ in Muradabad got a CT scan done and said that there was a growth in the brain but that it would resolve gradually with some medicines. Separately, most of the people in the village practise witchcraft, and there was a Brahmin girl who used 
to visit from Saharanpur and conduct hawans. I was taken to some of these hawans. But I believe these hawans are all ways of fooling people: offer this, bring that, donate money, pray to this god, and so on. I have seen so much of all this."

28-year-old woman, PWMD

\section{Discussion}

These findings suggest that PWMD in these two districts of western Uttar Pradesh are caught between the devil (a weak and inadequate public mental health sector) and the deep blue sea (unethical and irrational care in the private sector), which often leads to catastrophic household expenditure and impoverishment. They initially sought help from a wide range of providers; when one treatment failed to yield a positive health outcome, the affected person and their family proceeded to the next provider, a practice that others have also described among PWMD in India $(18,19)$. The care provided by allopathic public providers was predominantly inadequate (five- or tenminute consultations in a public psychiatric hospital setting) and treatment only pharmacological, while in the private sector it was also exclusively pharmacological and also irrational, and excessive (many more investigations and medicines than required) (20) . Thus, the unethical nature of health service provisioning (inadequate or not available) pushed people into the predatory private sector. This, in turn, led to the third theme of patient impoverishment due to catastrophic expenditure, which was followed by loss of hope and abandonment of help seeking.

The weaknesses in India's healthcare system have been summarised as including a weak primary-care sector, unequal distribution of skilled human resources (for example, there were no government psychiatrists in either of the rural districts in this study, despite a combined population of over 7 million people, a large unregulated private sector, low public expenditure on health, fragmented health information systems, and irrational use (and spiralling costs) of drugs and technology, accompanied by weak governance and poor accountability (18).

These characteristics of the wider health system almost act as a complicit network. For example, few psychiatrists are present in the public health system today, partially because mental health services are allocated a relatively small budget with few associated positions, and psychiatrists are therefore attracted to the unregulated and lucrative private medical sector. On the demand side, public services are not available or accessible (long distances to travel or long wait times), pushing people to attend private providers. Disciplinary boundaries such as those between psychology and psychiatry can divide mental health professionals, making them reluctant to empower or build capacity in areas such as primary care (19).

At the same time, there are some recent policy and programming initiatives that promise improved primary and mental health services. The Government of India has endorsed the goal of providing "universal access to good quality healthcare services without anyone having to face financial hardship as a consequence," which is set out in the National Health Policy of India of 2017 (21). Furthermore, since the data collection period of this study, the Central government has started mental health digital academies at institutes such as The National Institute for Mental Health and Neurosciences (NIMHANS), Bangalore, the central Institute of Psychiatry (CIP), Ranchi and LG Bordoloi (LGB) Institute, Tezpur, and 25 centres of excellence across the country (22). The Government of India's Mental Healthcare Act of 2017 also obliges states to provide affordable healthcare at a district level (23).

The unethical practices of practitioners described in this paper include over-investigation (requesting tests that are not indicated), polypharmacy (prescribing more medicines than are indicated in evidence-based algorithms of care), and irrational care (provision of "care," such as intravenous saline, that does not have an evidence base). These practices contravene the core ethics principles of autonomy, beneficence, non-maleficence, and justice. Each of these practices advantages the clinician as a source of income and disadvantages the patient with unnecessary and potentially harmful out-of-pocket expenditure that is at times catastrophic, health risks such as excess exposure to x-rays, side effects and drug reactions, and the risk of infections resulting from unnecessary intravenous administration. The widespread practice of over-investigation, fuelled by the system of financial kickbacks, has been recognised and discussed in other publications in India $(8,10)$. Polypharmacy is recognised as a problem prevalent in psychiatry globally, but particularly in India (20).

PWMD, already marginalised, are particularly vulnerable to unethical practices of private practitioners due to the nature of their mental illnesses, typically conditions that are stigmatising, disabling, complex, poorly understood, chronic, and relapsing. Mental distress has complex multidimensional socioeconomic determinants-such as poverty, social exclusion, and poor education - that interact and compound in a vicious circle to make PWMD further vulnerable (24).

The practice of public and private psychiatry across India, however, provides an almost exclusively pharmacological model of care. A study of the District Mental Health programme in Uttar Pradesh illustrated a dominant focus on delivering psychotropic medication to community members and a failure to address the psycho-social problems that were the cause of much mental distress (25).

This focus on medication is mirrored among private providers as well. A study of antidepressant medication and globalisation in India described how the antidepressant fluoxetine is promoted to specialist psychiatrists by representatives of pharmaceutical companies (26). By a process of the "floating prescription", which is carried by patients from provider to provider, patients are prescribed fluoxetine by biomedical and informal providers (such as rural medical practitioners). This predominantly pharmacological practice of psychiatry often fails to meet the needs of the PWMD who is not provided with effective care for depression, which should 
include talk therapy, family support, and building skills and knowledge for mental wellbeing (27). In the public sector in India, this approach of exclusive pharmacological treatment is structurally speaking, often the only feasible response, given the high numbers of patients and the low allocation of psychologists and psychiatrists, which limits the possibilities for psycho-social interventions. India needs to develop and implement comprehensive and effective systems to regulate both private and public psychiatrists and mental health service providers as well as systems to ensure ongoing quality of care and enforce standards of professional conduct at both the state and national levels $(6,8,12)$. This requires development and application of best-practice algorithms and protocols, including guidelines on the use of generic drugs, lab tests, and diagnostic imaging. These should be endorsed and regulated by professional bodies such as the Indian Psychiatric Society, the Indian Association of Private Psychiatry, and the Medical Council of India.

Secondly, while pharmacological agents provide healing for many people, there are others who experience ongoing symptoms, poor social relationships, and persistent disability, despite following the recommended pharmacological treatment, underlining the fact that mental distress operates in a complex interaction between culture, context, and illness. The interaction of explanatory framework, help seeking, and the use of magico-religious frameworks simultaneously with biomedical frameworks has been described in other studies in India $(28,29,30)$. For some, a non-biomedical explanation for persisting psycho-social disability (such as a religious framework of belief) is an important coping mechanism (30). Without attention to alternative explanatory frameworks, to the voices and participation of communities, and to non-pharmacological forms of care, initiatives for "global mental health" can lead to peddling of medicines and other biomedical accessories without providing psycho-social support or addressing core determinants of mental distress (26, 30).

Thirdly, study participants described multiple instances of visiting biomedical providers who did not provide them with evidence-based care. Key programmatic and policy responses must include building primary health provider capacity to deliver evidence-based diagnosis and management of mental illness, and also building the skills of primary healthcare practitioners to provide psycho-social as well as pharmaceutical mental healthcare, and broadly strengthened and ethical public mental health services with allocated supporting resources $(19,25)$.

The findings of this study additionally demonstrate that expenditure on investigations and care for mentally distressed family members can have catastrophic economic impacts. Distinguishing high out-of-pocket care and catastrophic expenditure is highly context specific; for vulnerable households, even a $10 \%$ increase in health expenditure can be catastrophic, leading to significant depression and suicidal ideation (31). Poverty is both a cause and outcome of mental distress (24), and the catastrophic impacts of seeking care (loss of land and income) described by participants in this study may have increased rather than eased mental distress.

\section{Methodological considerations}

This study identified participants using the convenience sampling approach, which risked excluding the most marginalised community members not known to project staff. However, a socio-demographic profile of participants provided in another publication by the lead author (32) shows strong representation by women, people from oppressed castes, and from the Muslim faith tradition, suggesting persons from marginalised groups were adequately represented.

There was a risk of social desirability bias in responses, given the identity of researchers as part of a local community mental health project. The positionality of the lead author as a woman of Western ethnic origin and as a leader within a local community health and development organisation working in the study area had the potential to influence the data collection and analysis by increasing responses that reflect programme in a positive light (social desirability bias), but also perceiving the researcher as an outsider, could have increased information sharing by participants through perceptions of researcher naivety to local contexts (33). Differences in power relations between researcher and participants can risk reduced participation, withholding of information, provision of misleading information, and reduced engagement by participants. It may contribute to participants providing socially desirable responses (33). There were several ways that social desirability bias and positionality were perhaps mitigated in community encounters and data analysis. Interviews were conducted by a local research assistant who was not part of the project team. The long-term residence of the first author in India, her wearing the attire typical for North Indian women, and her speaking fluent Hindi may have increased her social acceptability and cultural understanding. The analysis and findings were reviewed and discussed with the research assistant and local staff to increase comprehension.

\section{Conclusions}

This study has several important implications. In a context of multiple compounding psychological, biomedical, social, and structural health system factors that conspire against PWMD, multiple empowering and interacting policy and programme responses are required to address their needs. Nascent actions to increase resourcing of mental health services across India must address the currently low numbers of psychiatrists and psychologists in public service as well as ensure they have time and opportunity to provide psycho-social as well as pharmaceutical care.

Mental health however is impacted predominantly by determinants outside of mental health services, and other policy actions must therefore include strengthening of all public hospitals to meet people's needs, revitalisation of 
primary care, and ensuring that only non-profit hospitals with evidence of transparent and affordable care are empanelled for service delivery under government-sponsored insurance schemes. It is of critical importance that programmes must listen to local voices and priorities, address health determinants, build community participation, and promote mental health competence.

PWMD in North India have few options to access effective care, and at times, their distress is augmented through the unethical practices of private healthcare providers. Excessive out-ofpocket expenditure leads to catastrophic impoverishment for some families and can lead to loss of land and hunger. Irrational care is prevalent in the private sector and includes polypharmacy, excessive, and unnecessary investigation. Pharmacological treatments prevail among private and public providers, and almost no providers give psycho-social support or care. Universal healthcare, community-engaged mental health services and resources, and rigorously regulated systems for both public and private providers are all urgently needed.

\section{Conflict of interest statement}

All authors declare they have no competing interests.

Mr Neil Brosnahan (private donor) covered costs of one month's salary for a research assistant. The donor had no connection with the subject of research.

\section{*Declaration regarding prior publication of similar work:}

$K M$ declares that this paper was developed from data collected as part of her doctoral thesis (32) and one paragraph in this thesis summarises some of the findings above. Two other papers were written (profiling different facets) from the data that formed the basis of this paper and these are referenced and described in this paper $(15,16)$.

\section{References}

1. Patel V, Chatterii S, Chisholm D, Ebrahim S, Gopalakrishna G, Mathers C, Mohan V, Prabhakaran D, Ravindran RD, Reddy KS. Chronic diseases and injuries in India. Lancet. 2011 Jan 29;377(9763):413-28.

2. World Health Organisation. Mental health atlas 2011. Geneva: The Organisation; 2011.

3. Kedia S. The ambitious Mental Healthcare Bill is a step closer to a progressive India. YourStory.com. 2017 Apr 4 [cited 2019 Aug 5]. Available from: https://yourstory.com/2017/04/mental-healthcare

4. Murthy RS. Mental health initiatives in India (1947-2010). Natl Med J India. 2011 Mar-Apr;24(2):98-107.

5. Jacob K, Sharan P, Mirza I, Garrido-Cumbrera M, Seedat S, Mari JJ, Sreenivas V, Saxena S. Mental health systems in countries: where are we now? Lancet. 2007 Sep 22;370(9592):1061-77.

6. Phadke A. Regulation of doctors and private hospitals in India. Econ Pol Wkly. 2016 Feb 6;51(6):46-55.

7. Balarajan Y, Selvaraj S, Subramanian SV. Health care and equity in India. Lancet.2011 Feb 5;377(9764):505-15.

8. Nundy S, Desiraju K, Nagral S, editors. Healers or predators? Healthcare corruption in India. New Delhi: Oxford University Press; 2018.

9. Ghosh S. Catastrophic payments and impoverishment due to out-ofpocket health spending. Econ Pol Wkly. 2011 Nov 19;46(47):63-70.

10. Gadre A. India's private healthcare sector treats patients as revenue generators. BMJ. 2015 Feb 24;350:h826.
11. Sachan D. Tackling corruption in Indian medicine. Lancet. 2013 Nov 16;382(9905):e23-4.

12. Gadre A, Shukla A. Dissenting diagnosis: voices of conscience from the medical profession. New Delhi: Random House; 2016.

13. Sarkar P, Chakraborty K, Misra A, Shukla R, Swain SP. Pattern of psychotropic prescription in a tertiary care center: a critical analysis. Indian J Pharmacol.2013 May-Jun; 45(3):270-3.

14. Braun V, Clarke V. Using thematic analysis in psychology. Qual Res Psychol.2006;3(2):77-101.

15. Mathias K, Kermode MK, San Sebastian M, Koschorke M, Goicolea I. Under the banyan tree--exclusion and inclusion of people with mental disorders in rural North India. BMC Public Health. 2015 May 1;15:446.

16. Mathias K., Kermode M, San Sebastian M, Davar B, Goicolea I. An asymmetric burden: Experiences of men and women as caregivers of people with psycho-social disabilities in rural North India. Transcult Psychiatry. 2018 Aug; 56(1):76-102. doi:10.1177/1363461518792728.

17. Sharma VK, Lepping P, Cummins AG, Copeland JR, Parhee R, Mottram P. The Global Mental Health Assessment Tool--Primary Care Version (GMHAT/PC). Development, reliability and validity. World Psychiatry. 2004 Jun; 3(2):115-9.

18. Patel V, Parikh R, Nandraj S, Balasubramaniam P, Narayan K, Paul VK, Kumar AK, Chatterjee M, Reddy KS. Assuring health coverage for all in India. Lancet. 2015 Dec 12;386(10011):2422-35.

19. Jacob KS. Repackaging mental health programs in low- and middleincome countries. Indian J Psychiatry. 2011 Jul-Sep;53(3):195-8.

20. Kukreja S, Kalra G, Shah N, Shrivastava A. Polypharmacy in psychiatry:a review. Mens Sana Monogr. 2013 Jan;11(1):82-99.

21. Ministry of Health and Family Welfare, Government of India. National Health Policy 2017.New Delhi:MOHFW;2017 [cited 2019 Aug 5].Available from: https://mohfw.gov.in/sites/default/files/9147562941489753121. pdf

22. National Institute of Mental Health and Neurological Sciences. (2019). NIMHANS Digital academies - translating best practices. Technology for training and transformation. Retrieved from http:// nimhansdigitalacademy.in/

23. Ministry of Law and Justice, Government of India. The Mental Healthcare Act (2017). New Delhi:MoLJ;2017 Apr 17[cited 2019 Aug 5]. Available from: https://www.prsindia.org/uploads/media/Mental\%20Health/ Mental\%20Healthcare\%20Act,\%202017.pdf

24. Lund C, Breen A, Flisher AJ, Kakuma R, Corrigall J, Joska JA, Swartz L, Patel V. Poverty and common mental disorders in low and middle income countries: a systematic review. Soc Sci Med. 2010 Aug 10;71(3):517-28.

25. Jain S, Jadhav S. Pills that swallow policy: clinical ethnography of a Community Mental Health Program in northern India. Transcult Psychiatry. 2009 Mar;46(1):60-85.

26. Ecks $S$, Basu $S$. The unlicensed lives of antidepressants in India: generic drugs, unqualified practitioners, and floating prescriptions. Transcult Psychiatry. 2009 Mar;46(1):86-106.

27. National Institute for Health and Clinical Excellence (NICE). Depression in adults: recognition and management. [Clinical Guideline 90]. London: NICE;2009 Oct, updated 2018 Apr [cited 2019 Aug 5]. Available from: https://www.nice.org.uk/guidance/cg90

28. Johnson S, Sathyaseelan M, Charles H, Jeyaseelan V, Jacob KS. Insight, psychopathology, explanatory models and outcome of schizophrenia in India: a prospective 5-year cohort study. BMC Psychiatry. 2012 Sep 27;12:159.

29. Bayetti C, Jadhav S, Jain S. The Re-covering Self: a critique of the recovery-based approach in India's mental health care. Disabil Global South. 2016;3(1):889-909.

30. Mills C. Decolonizing global mental health: the psychiatrization of the majority world. New York: Routledge; 2014.

31. Brinda EM, Rajkumar AP, Enemark U, Prince M, Jacob KS. Nature and determinants of out-of-pocket health expenditure among older people in a rural Indian community. Int Psychogeriatr. 2012 Oct;24(10):1664-73.

32. Mathias K. Shadows and light: examining community mental health competence in North India. Umea, Sweden: Umeå University; 2016.

33. Sultana F: Reflexivity, positionality and participatory ethics: Negotiating fieldwork dilemmas in international research. ACME Int E-Journal Crit Geogr. 2007;6(3):374-85. 